\title{
JUEGO, SÍMBOLO Y FIESTA EN CONCIERTO BARROCO DE ALEJO CARPENTIER, UNA MIRADA DESDE LA MÚSICA
}

\author{
Carlos Paz Barahona
}

\begin{abstract}
RESUMEN
El presente artículo propone una interpretación de la novela Concierto barroco del escritor Alejo Carpentier, utilizando para ello las herramientas de la hermenéutica de Hans Georg Gadamer: el juego, el símbolo y la fiesta, partiendo, a su vez, de un universo musical presente en la obra que es también preocupación constante en la vida del autor: la música latinoamericana.

Palabras clave: Alejo Carpentier, Concierto barroco, hermenéutica, Hans Georg Gadamer, música latinoamericana.
\end{abstract}

\section{ABSTRACT}

This article propose an interpretation of Alejo Carpentier's novel Concierto Barroco following the tools of Hans Georg Gadamer: play, symbol and feast, starting from a musical universe present in the work of the autor and anxiety of his life: the Latin American music.

Key words: Alejo Carpentier, Concierto Barroco, Hans Georg Gadamer, latinoamerican music.

El camino trazado en el presente artículo para lograr un acercamiento a la novela Concierto barroco de Alejo Carpentier es el de la música en sus funciones lúdica, simbólica y festiva, con el objetivo de observar la manera como el mundo de los sonidos, de una o de otra forma -en sus géneros, en sus instrumentos, en sus autores, en sus prácticas- transita por el tejido textual y se imbrica en la red de sentidos de éste.

El instrumental de la hermenéutica del arte ofrecido por Gadamer proviene de una visión antropológica de la experiencia estética como punto de partida para trazar la genealogía de lo bello mediante la recuperación de un instrumental clásico. Así, el concepto griego de Kalós - lo bello - sirve a Gadamer para extraer, como rasgo fundamental, su autodeterminación. Lo bello se autodetermina y se representa a sí mismo.

Carlos Paz Barahona. Profesor de la Escuela de Estudios Generales de la Universidad de Costa Rica. San Pedro, San José, Costa Rica.

Recepción: 16-03-2005

Aceptación: 17-03-2005 
Esto conduce a Gadamer al concepto de belleza libre de Kant, que es belleza libre de conceptos y significados, punto de encuentro del placer desinteresado y de la finalidad sin fin; sin embargo, renuncia al subjetivismo kantiano acudiendo a la consideración del arte como experiencia antropológica a través de tres conceptos clave: juego, símbolo y fiesta, conceptos tan antiguos como la humanidad misma.

El juego como exceso, intenso y repetitivo, se constituye en base antropológica que explica la tendencia innata del hombre al arte. El juego como automovimiento que no tiende a una meta o un final, el movimiento en cuanto movimiento. Estos conceptos unidos a los de autonomía y desinterés de Kant, llevan a Gadamer a definir el arte como juego en la forma de autonomía del movimiento, sin que esto signifique la consideración de la obra de arte como cerrada y consolidada, sino más bien dinámica, donde la obra se entiende como proceso continuo de construcción y reconstrucción que deja un espacio abierto por rellenar: es el espacio del juego.

El símbolo griego, como tablilla dividida en dos partes que se compartía entre anfitrión y huésped, sirve a Gadamer para evocar el sentimiento de lo bello como un orden íntegro posible, como un insoluble juego de contrarios de mostración y ocultación donde lo universal tiene lugar en lo particular sin que necesariamente se dé lo contrario; lo simbólico del arte facilita, por consiguiente, el reconocimiento del origen y la captación de la permanencia en lo fugitivo. Frente al automovimiento del juego tenemos el autosignificado del símbolo.

En el carácter de fiesta de la obra de arte, Gadamer destaca el tema de la superación del tiempo. La experiencia estética es un tiempo de celebración que rompe con el presente y abandona la idea del tiempo lineal y acumulativo para presentarlo eterno. Arte es el despojo del tiempo. La fiesta es también identidad comunitaria, niega todo aislamiento, es congregación.

La ruptura de la estructura del tiempo en la celebración de la fiesta es común en las culturas primitivas y sirve como base antropológica para la consideración de la obra de arte como un conjunto de modos de representación determinados por el tiempo de la congregación y la celebración.

\section{Carpentier y la música}

Como es conocido, en la obra en general de Alejo Carpentier encontramos el aspecto de la música no solo como tema, sino como parte integral de sus herramientas escriturales y estructurales. En el tema político, en el discurso identitario, en el tema de la conquista, etc., está presente la música; pero no como telón de fondo o como ambientación, sino como parte de la polifonía de una gran partitura textual; reconocido esto por el mismo autor cuando menciona que "la arquitectura y la música, artes paralelas, influyeron en mi formación. (Además, esto es visible en todos mis libros.)" (Arias 1975: 16). Asimismo, en una entrevista, Carpentier contesta a su interlocutor, Salvador del Río:

\footnotetext{
Ahora me hace usted regresar a 'mi violín de Ingres', violín que a menudo suena gratamente - acaso más gratamente que la misma literatura - en el compositor malogrado que, desde la adolescencia, convive en mí con el escritor (En Carpentier 1987: 193).
}

Podemos entender, entonces, que la colección de colaboraciones periodísticas de Carpentier en diversos diarios reunida por primera vez y publicada por la editorial siglo veintiuno de México tenga por título Ese músico que llevo dentro.

Para acercarnos a una idea del papel de la música en la obra de Alejo Carpentier, debemos remitirnos a revisar algunos antecedentes que denotan la existencia de una práctica musical de primera línea que constituía costumbre en el ámbito familiar: 
Mi abuela era una excelente pianista, alumna de César Frank - de quien conservo algunas cartas inéditas, dirigidas a ella. Mi madre lo era también. y bastante buena. Mi padre, que quiso ser músico antes que arquitecto, empezó a trabajar el violoncello con Pablo Casals (Arias 1975: 15).

Mucho antes que cualquier otra actividad literaria, Alejo Carpentier se iniciaba en la formación musical que si bien no llegó muy lejos técnicamente, resultó para él una experiencia significativa, ante todo para comprender la música en aspectos compositivos difíciles de entender para el simple escucha, como por ejemplo la estructura, la textura y la tonalidad de una obra. Dice Alejo Carpentier:

Aprendí música a los once años, llegando a tocar el piano con pasmosa rapidez. A los doce tocaba páginas de Bach, de Chopin, con cierta autoridad. Pero en modo alguno pretendía ser eso que llaman 'un intérprete'. Utilizaba el piano como medio de conocimiento de la música. Nada más (16).

Este contacto temprano con la música es lo que le permitirá al escritor concebir sus obras escénico-musicales de tal manera que no sea posible prescindir del elemento musical al estar plenamente integrado con el texto:

Mis textos destinados al teatro: dos ballets y una ópera bufa, están concebidos para músicos y en función de la música. Sin la música que los acompañan, no tendrían vida autónoma (41).

La formación musical básica recibida fue de suma importancia, pero no mayor que el amplio conocimiento sobre el gran repertorio musical que adquiriría en sus viajes y estancias por diferentes países, el intercambio con grandes personalidades de la cultura y el arte, así como la investigación que realizó sobre la música en Cuba -publicada en 1946- por encargo de la casa editorial Fondo de Cultura Económica de México, lo que le permitió un profundo conocimiento del desarrollo musical de su país, proceso de fusiones de estilos, mezcla de épocas y escuelas, comunes a la mayoría de los países latinoamericanos. Y es por estas razones que Carpentier dice:

La música está presente en toda mi obra. En El siglo de la luces, por ejemplo, Carlos toca la flauta, el protagonista de Los pasos perdidos es un músico y El acoso está estructurada en forma sonata: primera parte, exposición, tres temas, diecisiete variaciones y conclusión o coda. Un lector atento que conozca de música puede observar fácilmente este desarrollo (67).

Sin embargo estos escasos ejemplos que da el escritor no reflejan en lo más mínimo la real proporción y frecuencia con que sus obras entran en un verdadero diálogo con el elemento musical.

La música en la obra de Alejo Carpentier se filtra por entre los espacios de la palabra, adquiriendo funciones complejas dentro del texto que se relacionan con la concepción del tiempo, procesos de simbolización, estructuración del relato y otros.

\section{Concierto barroco}

En su estudio sobre la novela Concierto barroco, Mercedes González Kreysa (1998) propone una estructura compuesta por dos voces contrastantes correspondientes a dos puntos de vista de análisis: el punto de vista de la fuga y el punto de vista del concerto grosso. Bajo la perspectiva de la fuga, opera la técnica compositiva del contrapunto polifónico donde el sujeto o 'dux' (Amo) expone un tema, que es nuevamente presentado por el contrasujeto (Filomeno), siguiendo a esto una réplica, respuesta o 'comes' (Vivaldi, Handell, Scarlatti). De esta forma dux y comes, tema y respuesta es América y Europa en continuo juego de construcción y reconstrucción de elementos musicales, culturales e identitarios. 
La concepción de Carpentier sobre el arte europeo de principios del siglo XX trata de que es un arte gastado mientras que el arte latinoamericano es un arte vivo (Cfr. Arias 1975: 18); esto explica la inversión en la dinámica del intercambio cultural sugerido en la novela: América propone, Europa responde. América es primera voz $(d u x)$, Europa es respuesta (comes) al impulso americano. Las voces que se relacionan en este contrapunto constituyen las partes en el juego. El movimiento del juego implica un jugar-con, un hacer comunicativo en un movimiento de vaivén (Gadamer 1991: 69).

Lo que se queda y lo que se va, traer y llevar en el espacio del juego se describen en la novela de la forma que sigue:

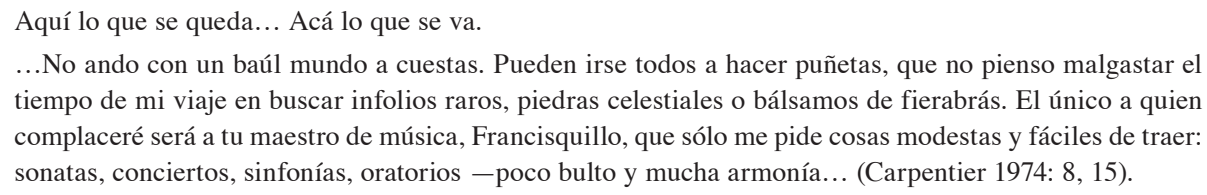

En el movimiento del juego se inscribe la expectativa de lo inesperado del resultado. Así, de todas aquellas partituras, instrumentos musicales, géneros y prácticas musicales venidas de Europa, se devuelve a esta algo que no prevé y que a su vez determina la continuación del juego. Estando en La Habana, el amo presta atención a quien le acompañará en su viaje por Europa, el negro Filomeno que:

\footnotetext{
...rasguea una guitarra de mala pinta, o, que cuando le vienen otras ganas, canta irreverentes coplas que hablan de frailes garañones y guabinas resbalosas, acompañándose de un tambor, o, a veces, marcando el ritmo de los estribillos con un par de toletes marineros cuyo sonido, al entrechocarse, es el mismo que se oye - martillo con metal - en el taller de los plateros mexicanos (19).
}

La dialogía, las voces y la polifonía del esquema bajtiniano utilizado por González Kreysa es la perspectiva lúdica del marco Gadameriano en el que inscribimos nuestro estudio.

El punto de vista del concerto grosso, señala González (Cfr. 1998: 62), está relacionado ante todo con la idea del viaje. Es un viaje en cuatro movimientos donde a lo largo de cuatro partes se suceden los tutti (Vivaldi, Handell, Scarlatti) y los concerti (Amo, Filomeno) en alternancia dialógica. Los cuatro movimientos son: I Veracruz-Habana, II España, III Venecia, IV París-Veracruz.

Este es un viaje con retorno al punto de partida que bajo muestra perspectiva teórica es un vaivén donde el concepto de juego exhibe su propiedad de continua renovación, el sujeto de la experiencia lúdica no es el mismo, así como el juego no es el mismo en cada uno de sus movimientos. Dice el Amo Montezuma hacia el final de la obra:

\section{Y, de pronto, me sentí como fuera de situación, exótico en este lugar, fuera de sitio, lejos de mí mismo y} de cuanto es realmente mío (Carpentier 1974: 76).

Posición diametralmente opuesta a la exhibida por el Amo al inicio de la obra antes de iniciar el viaje.

Desde la perspectiva del autor, existe un elemento lúdico, si bien extratextual, no por ello carente de interés. Carpentier escribe su Concierto barroco a partir de un hecho verídico del que se enteró por medio de un amigo compositor italiano llamado Francesco Malipiero, de quien dice Carpentier: 
Esto capta un interés inicial, pero no es sino años después que Carpentier recibe nuevas pistas sobre esta ópera de Vivaldi por vía del musicólogo Roland de Candé y tiene acceso a los únicos documentos conservados que son la portada, el argumento de Alvise Giusti, la escenografía de cada uno de los tres actos y la descripción de los personajes. La partitura musical se considera perdida, según lo confirma el Diccionario Oxford de la Música. Sin embargo, estrenada la ópera en el teatro de Sant' Angelo en el año 1733, relata Carpentier en una nota al final de su novela:

\footnotetext{
Tanto parece haber gustado el Moctezuma de Vivaldi - que traía a la escena un tema americano dos años antes de que Rameau escribiera Las Indias galantes, de ambiente fantasiosamente incaico- que el libreto de Alvise (otros lo llaman Girolamo) Giusti, habría de inspirar nuevas óperas basadas en episodios de la conquista de México a dos célebres compositores italianos: el veneciano Baldassare Galuppi (1706-1785), y el florentino Antonio Sacchini (1730-1786) (Carpentier 1974: 92).
}

Tal parece que el encuentro casual con la información de una ópera desconocida de temática americana - la primera que se conozca - atrapó la atención del autor, quien se dio a la tarea de concebir su novela Concierto barroco, publicada en 1974.

La acción se inicia en América algunos meses antes del estreno de la ópera en Venecia y culmina con un juego de tiempos y espacios que llega hasta el siglo veinte, poco más de los doscientos años que duró el olvido de Vivaldi.

Encontramos en toda la génesis de esta novela un aspecto importante que se relaciona con la dimensión lúdica de la obra de arte, entendido esto, de acuerdo con Gadamer, no solo "de un modo negativo, como libertad de estar sujeto a un fin, sino como un impulso libre" (Gadamer 1991: 66). La ópera perdida constituyó para el autor una invitación al juego, un impulso a la imaginación, una vereda abierta, un espacio libre para la representación. Esta dimensión lúdica presenta aquí otros registros; uno de ellos se relaciona con la incompletitud de la obra de arte, como lo señala Gadamer: "Toda obra deja al que la recibe un espacio de juego que tiene que rellenar" (73). En el nivel de producción de la obra, la ausencia de la partitura musical de esta ópera de Vivaldi, única de tema americano escrita por él, generó en el autor de la novela la escritura de una 'partitura textual', que de alguna manera puede verse como ese impulso por completar el juego de la ópera incognoscible en un espacio de libertad creadora, libertad de representación que no se agota allí, sino que continúa su relación de juego en el nivel de la recepción de la obra en el momento en que cada lector y cada lectura de éste dialoga con el texto en un espacio lúdico libre, cada quien construye su propia ópera, su propio mundo sonoro irrepetible.

La dimensión lúdica en los géneros musicales la encontramos desde las primeras páginas de la novela antes de la partida hacia Europa, cuando Francisquillo, el criado, canta para el Amo y su visitante nocturna Las Mañanitas del Rey David (canción tradicional mexicana):

antes de pasar a las canciones del día, que hablaban de hermosas ingratas, quejas por abandonos, la mujer que quería yo tanto y se fue para nunca volver, y estoy adolorido, adolorido, adolorido, de tanto amar (12).

Canciones que por la temática sugieren ser boleros, para luego, a solicitud del Amo de que cantara algo más moderno, Francisquillo canta entonces $A h$, dolente partita (copla italiana) y A un giro sol di bell'occhi lucenti (madrigal italiano).

Las Mañanitas... es una canción tradicional probablemente del siglo diecinueve; el bolero (no el español) surgió a principios del siglo veinte en México; el madrigal es una forma musical vocal del Renacimiento en Italia — siglo dieciséis-, y la acción en la novela sucede a principios del siglo dieciocho.

Este juego de géneros y estilos está construido en un movimiento de vaivén (Gadamer 1991) donde el tiempo envía y reenvía sin orden aparente un género o un estilo de canción de un sitio a otro 
y de un tiempo a otro. Es también esto un preámbulo de las características de la dimensión lúdica en el tratamiento del tiempo que se desarrollará a lo largo de toda la novela. Así, como vemos la transposición temporal de géneros musicales, vemos también la transposición de autores musicales que transgreden el orden del tiempo. Al otorgar a la experiencia estética el movimiento del juego, aunado al tiempo de la fiesta, arribamos a lo que González caracteriza musicalmente como stretto - estrecho-, momento en que el tiempo se comprime y se presenta el tema en forma condensada y que metafóricamente deviene en quiebre temporal de la trama (1998: 61):

De pronto, ante una tumba cercana que desde hacía rato miraba porque, en ella, se ostentaba un nombre de sonoridad inusitada en estas tierras. -IGOR STRAVINSKY - dijo deletreando (Carpentier 1974: 53).

El gran compositor ruso (1882-1971) aparece muerto en el siglo XVIII de la novela y el gran compositor alemán del siglo XIX, Richard Wagner (1813-1883), ha muerto recién el día anterior:

\footnotetext{
Al pasar frente al palacio Vendramin-Calergi notaron Montezuma y Filomeno que varias figuras negras — caballeros de frac, mujeres veladas como plañideras antiguas- llevaban, hacia una góndola negra, un ataúd con fríos reflejos de bronce. — «Es de un músico alemán que murió ayer de apoplejía — dijo el barquero, parando los remos-: Ahora se llevan los restos a su patria. Parece que escribía óperas extrañas, enormes, donde salían dragones, caballos volantes, gnomos y titanes, y hasta sirenas puestas a cantar en el fondo de un río (56-7).
}

Cierra el ciclo de los compositores del stretto (de la fractura del tiempo) el norteamericano Louis Armstrong (1901-1971), trompetista y vocalista jazz. Nótese que los compositores europeos se encuentran vinculados a la muerte, al pasado. La lápida de Stravinsky y el féretro de Wagner en contraste con la vitalidad y actualidad de Louis Armstrong, pues los carteles:

anunciaban que dentro de un momento, empezaría a sonar el cobre impar de Louis Armstrong... Y apareció en truenos, grandes truenos que lo eran de aplausos y exultación, el prodigioso Louis. Y, embocando su trompeta, atacó, como sólo él sabía hacerlo, la melodía de Go down Moses... (82-3).

Encontramos aquí una declarada reivindicación de los valores de la música popular americana residentes ante todo en el elemento rítmico. La Europa de las armonías añejas muere frente a la vitalidad de la música jazz, música afroamericana, producto de la mezcla de culturas y digna de cualquier teatro europeo.

Existe también una dimensión lúdico-simbólica en el instrumental musical que se menciona en la novela, en donde aparecen instrumentos europeos que hoy llamaríamos "de época", como la vihuela, la mandolina, rabel, basso di gamba, chitarrone, clavicemballo, etc., en imbricada mezcla con instrumentos latinoamericanos indígenas como zampoñas, tipinaguas, sonajas, marugas, tambores y algunos instrumentos producto de la hibridación cultural, como la vihuela mexicana, el órgano de palo, clarincillos, etc. Agregamos a esta lista el instrumental utilizado por el negro Filomeno en su aclamada improvisación durante el concierto en el Ospedale de la Pietá de Venecia - concerto grosso dirigido por Antonio Vivaldi, que terminó en una fiesta delirante- donde a falta de sus tambores y su guitarra, tomó los utensilios que encontró más a mano como cucharas, calderos de cobre, espumaderas, batidoras, rollos de amasar, tizones y palos de plumeros haciendo de ellos una batería de percusión con la cual intervino en la orquesta femenina del Ospedale, causando la euforia total y la admiración de los grandes maestros presentes (Haendel, Scarlatti y Vivaldi, quien dirigía el concierto).

Estos grupos instrumentales nos remiten, pues, a las funciones simbólicas que guardan y que se relacionan con el gran tema de las obras de Carpentier que es la identidad latinoamericana. Tal como dice Miguel Rojas Mix, parafraseando a Ortega y Gasset, "La identidad, como la vida, es un gerundio, un continuo hacerse del ser... es la situación del ser, precisada 
en el tiempo y en el espacio.” (Rojas Mix 1991: 32). Y es en este juego de intercambios instrumentales sorprendentes, inverosímiles, en donde asistimos a la representación del movimiento del tiempo, del espacio, de los objetos en el gran teatro de la hibridación. Siguiendo a Rojas Mix, el abuelo español, el abuelo indígena, el abuelo africano y el abuelo inmigrante, cada uno representado por su aporte al instrumental musical americano en un juego único de fronteras desdibujadas, configuran ese complejo mapa musical latinoamericano, pero a la vez tan natural y tan claro como un simple juego.

La dimensión simbólica del espacio en la novela Concierto barroco la podemos entender como un espejo de la travesía de la conquista realizada por Colón. De acuerdo con Gadamer, el símbolo en la obra de arte "no sólo se remite a algo, sino que en ella está propiamente aquello a lo que se remite" (Gadamer 1991: 91), de manera que el viaje del Amo y su servidor a Europa no es una representación del viaje invertido de Colón, sino que es el viaje en sí mismo, en su narrativa, en sus desembarcos, en sus espacios. Recordemos que aunque hay una relación exactamente inversa en el itinerario de Colón (Italia-España-Islas del Caribe-México) y el itinerario del Amo (México-Islas del Caribe-España-Italia), el periplo del Amo tiene un significado en sî mismo, que es la toma de conciencia de la propia identidad por medio de la mirada del otro. Esa conciencia de sí como otro en México, y que se atribuía el Amo antes de su partida a conocer las tierras de sus antepasados, se transforma en una conciencia de sí como mismo al identificarse con su "latinoamericanidad" al otro lado del océano. Y es este precisamente el desenlace del conflicto, pues en medio de la representación de la ópera Moctezuma de Vivaldi, ante un cúmulo intolerable de falsos históricos y de equívocos en el libreto, dice para sí el Amo:

\footnotetext{
Y, de pronto, me sentí como fuera de situación, exótico en este lugar, fuera de sitio, lejos de mí mismo y de cuanto es realmente mío... A veces es necesario alejarse de las cosas, poner un mar de por medio, para ver las cosas de cerca (Carpentier 1974: 76).
}

La dimensión festiva de la práctica musical se presenta a lo largo de toda la novela, pues guarda un tono mezcla de humor y erotismo que se relaciona, pensando en Gadamer, con el goce, la celebración, la congregación (Cfr. Gadamer 1991), anclados estos aspectos casi siempre a episodios en los que se encuentra la música presente.

No obstante, los momentos de mayor importancia para visualizar la dimensión festiva en la novela son, por supuesto, el concierto barroco en el Ospedale de la Pietá y la representación de la ópera Moctezuma en el Teatro di Sant'Angelo en Venecia. Ambos tienen un sentido y un desenlace diferente. El primer momento une y el segundo separa; el primero es convergencia y el segundo es divergencia; el primero es celebración y el segundo es congregación; el primero es encuentro y el segundo es ruptura; el primero es cerrado en sí mismo, el segundo es abierto en posibilidades. Sin embargo, ambos momentos, como dimensión festiva, forman una unidad integral necesaria para configurar en la novela el tiempo de la fiesta establecido por el carnaval de epifanía en la Venecia de la novela. El concerto grosso en el Ospedale de la Pietá es la celebración de la música, de su propio tiempo y de su automovimiento que se complace en el gozo del hacer en comunidad:

\footnotetext{
Prendido el frenético allegro de las setenta mujeres que se sabían sus partes de memoria, de tanto haberlas ensayado, Antonio Vivaldi arremetió en la sinfonía con fabuloso ímpetu... Doménico Scarlatti se largó a hacer vertiginosas escalas... Jorge Federico Haendel se entregaba a deslumbrantes variaciones... (Carpentier 1974: 42).
}

Se une a esta fiesta concertante el elemento americano por medio de la intervención del negro Filomeno, quien, entretanto: 
Había corrido a las cocinas, trayendo una batería de calderos de cobre de todos los tamaños a los que empezó a golpear con cucharas, espumaderas, batidoras, rollos de amasar, tizones, palos de plumeros, con tales ocurrencias de ritmos, de síncopas, de acentos encontrados, que, por espacio de treinta y dos compases lo dejaron solo para que improvisara. — ¡Magnífico! ¡Magnífico!» — gritaba Jorge Federico. —« Magnífico! ¡Magnífico!» - gritaba Doménico.

Vemos aquí la convergencia de músicas diferentes en congregación de elementos, donde a la música tradicional europea se une la diversidad instrumental americana, un nuevo tratamiento del ritmo y la facilidad creadora de la improvisación. El concepto de hibridación cultural claramente presente se evidencia hacia el final del concierto mediante la imagen de la mezcla en una bebida:

Las pupilas del Ospadale prorrumpieron en una enorme carcajada, mientras Montezuma hacía correr las copas de una bebida que había inventado, en un trasiego de jarras y botellas, mezclando de todo un poco... (44).

El tiempo de la fiesta se instaura como matriz generadora de la diversa y extensa riqueza musical latinoamericana: colorida, explosiva, vital, delirante. En esta fiesta caen dos mitos centrales: el de la seriedad de la música llamada 'seria' y el de la simplicidad de la música popular latinoamericana. Ambos mitos se derrumban ante el fenómeno de la hibridación, el cual exige nuevos parámetros estéticos, nuevos derroteros teóricos que Carpentier se encarga de reclamar en su Concierto barroco.

\section{Bibliografía}

Arias, Salvador (comp.). 1975. Recopilación de textos sobre Alejo Carpentier. La Habana: Casa de las Américas. Centro de Investigaciones Literarias.

Bogdanov, Vladimir; Chris Woodstra y Stephen T. Erlewine. 2001. All Music Guide to Popular Music. Miami: AMG All Media Guide.

Carpentier, Alejo. 1974. Concierto barroco. La Habana: Editorial Arte y Literatura.

1987. Obras completas, Vol. XII: ese músico que llevo dentro 3 / la música en Cuba. México: Editorial Siglo Veintiuno.

Gadamer, Hans Georg. 1977. Verdad y método. Salamanca: Ediciones Sígueme.

1991. La actualidad de lo bello. Barcelona: Paidós.

1998. Arte y verdad de la palabra. Barcelona: Paidós.

1998a. Estética y hermenéutica. Madrid: Tecnos.

González Kreysa, Mercedes. 1998. Concierto barroco: una transmutación plástico-musical en torno a la identidad latinoamericana. Tesis de grado Magíster Literarum en Literatura Latinoamericana, Universidad de Costa Rica. San José: Ciudad Universitaria Rodrigo Facio.

Kelemen, Pál. 1951. Baroque and Rococo in Latin America. New York: MacMillan.

Rojas Mix, Miguel. 1991. Los cien nombres de América. Eso que descubrió Colón. San José: Editorial de la Universidad de Costa Rica. 